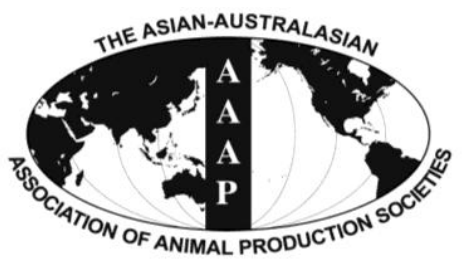

Asian Australas. J. Anim. Sci.

Vol. 26, No. 11 : 1523-1528 November 2013

http://dx.doi.org/10.5713/ajas.2013.13413

www.ajas.info

pISSN 1011-2367 elSSN 1976-5517

\title{
Genome-wide Association Study of Chicken Plumage Pigmentation
}

\author{
Mi Na Park, Jin Ae Choi, Kyung-Tai Lee, Hyun-Jeong Lee, Bong-Hwan Choi, Heebal Kim', \\ Tae-Hun Kim, Seoae Cho ${ }^{2}$, and Taeheon Lee ${ }^{1, *}$ \\ Division of Animal Genomics and Bioinformatics, National Institute of Animal Science, \\ Rural Development Administration, Suwon, Korea
}

\begin{abstract}
To increase plumage color uniformity and understand the genetic background of Korean chickens, we performed a genome-wide association study of different plumage color in Korean native chickens. We analyzed 60K SNP chips on 279 chickens with GEMMA methods for GWAS and estimated the genetic heritability for plumage color. The estimated heritability suggests that plumage coloration is a polygenic trait. We found new loci associated with feather pigmentation at the genome-wide level and from the results infer that there are additional genetic effect for plumage color. The results will be used for selecting and breeding chicken for plumage color uniformity. (Key Words: Chicken, Plumage Pigmentation, Genome-wide Association Study)
\end{abstract}

\section{INTRODUCTION}

Poultry industry, in the process of rapid industrialization, developed commercial chicken strains from a small number of breeds. To increase the productivity of native chickens, they were bred for economic traits. Although this process resulted in higher productivity, at the same time it decreased genetic diversity (Tadano et al., 2007). In recent years, it has become increasingly important to protect national endemic genetic resources and use local breeds to create commercial strains that can adapt to the changing environment.

In Korea, the National Institute of Animal Science (NIAS) has been studying the process of indigenization of foreign breeds in to Korea and methods to restore Korean native chicken breeds. Korean native chickens (KNCs) as defined by NIAS in 2008 are chickens that have been bred true for at least seven generations. The commercial KNC called Woorimatdag (WR CC) was developed by crossing three native chicken breeds (Heo et al., 2011).

\footnotetext{
* Corresponding Author: Taeheon Lee. Tel: +82-2-880-4822, Fax: +82-2-883-8812, E-mail: taeheon@snu.ac.kr

${ }^{1}$ Department of Agricultural Biotechnology, Animal Biotechnology Major, and Research Institute for Agriculture and Life Sciences, Seoul National University, Seoul 151-742, Korea.

${ }^{2}$ C\&K genomics, Seoul National University Research Park, Seoul 151-919, Korea.

Submitted Jul. 10, 2013; Accepted Sept. 4, 2013; Revised Oct. 10, 2013
}

Woorimatdag has contributed to the industrialization of KNCs because of its rapid growth and the texture of the meat in comparison to the native chickens (Park, 2010). However, the use KNC H strain in the paternal line to create Woorimatdag has led to the decrease in plumage uniformity. Unlike typical white broilers, KNCs usually have colored feathers and various pigmentation patterns. Plumage color is an important factor that is used by consumers to distinguish between KNC strains. Although plumage color is easily observed, the genetics behind the feather coloration is governed by both qualitative and quantitative features (Klungland and Vage, 2000). In chickens, mutations in MC1R and TYR genes have been shown to be associated with feather pigmentation (Kerje et al., 2003; Liu et al., 2010). However, there is a lack of research on the genetics of plumage coloration in Korean chicken at the genomewide scale. The purpose of this study is to characterize the genetic polymorphism underlying different plumage color using the chicken $60 \mathrm{~K}$ SNP chip through GWAS (genomewide association study) and to increase plumage color uniformity of Woorimatdag. The results will also be used for selecting and breeding $\mathrm{KNC} \mathrm{H}$ strain.

\section{MATERIALS AND METHODS}

\section{Sample and phenotype collection, and genotyping}

A total of 274 samples from four KNC strains were collected from NIAS. It comprised of $245 \mathrm{KNC} \mathrm{H}$ strains 
(KNCH), 9 KNC S stains (KNCS), 9 KNC R stains (KNCR), and $11 \mathrm{KNC} \mathrm{L} \mathrm{strains} \mathrm{(KNCL).} \mathrm{The} \mathrm{plumage}$ colors of these strains range from black, black with brown, brown, red-brown, and black. KNC $\mathrm{H}$ strain chickens can have black to black and brown plumage and the individuals were classified into seven categories according to the number of body parts it exhibited brown plumage. Plumage color was scored for six specific body parts: head, neck, breast, back, wings, and tail. If the individual only had black feather, it was given a score of zero, however, if an individual showed brown plumage, for every body part it had brown it received 1 point. This classified the individuals into seven categories, ranging from all black to brown in all scored body parts. Blood samples were collected in EDTA tubes and DNA was extracted using Wizard genomic DNA purification kit (Promega, USA) according to the manufacturer's instruction. The genomic DNA samples were genotyped using the 60K SNP Illumina iSelect chicken array (Illumina Inc., USA).

\section{Genome-wide association test}

The 60K SNP Illumina iSelect chicken array contains 57,637 SNPs that are distributed across the chicken genome. SNPs were excluded if it had a missing rate of $>5 \%$, a minor allele frequency (MAF) of $<0.01$, or a HardyWeinberg equilibrium ( $H W E$ ) test p-value of $<10^{-6}$ using PLINK 1.07 (Purcell et al., 2007). After the quality control, 53,257 SNPs were retained for further analysis. GWAS analyses on plumage coloration of whole body and the body parts traits were performed using mixed model of GEMMA (v0.93) (Zhou and Stephens, 2012), which accounts for population stratification and sample structure.

$$
\begin{aligned}
& \mathrm{y}=\mathrm{W} \alpha+\mathrm{x} \beta+\mathrm{u}+\varepsilon, \\
& \mathrm{u} \sim \mathrm{MVN}_{n}\left(0, \lambda \tau^{-1} \mathrm{~K}\right), \varepsilon \sim \operatorname{MVNn}\left(0, \tau^{-1} I_{n}\right)
\end{aligned}
$$

Where $\mathrm{y}$ is an $\mathrm{n}$-vector of traits (plumage coloration) for $\mathrm{n}$ individuals; $\mathrm{W}=\left(\mathrm{w}_{1}, \mathrm{w}_{2}, \ldots, \mathrm{w}_{c}\right)$ is an $\mathrm{n} \times \mathrm{c}$ matrix of covariates (fixed effects) including a column of $1 \mathrm{~s}$; $\alpha$ is a cvector of the corresponding coefficients including the intercept; $x$ is an n-vector of marker genotypes; $\beta$ is the effect size of the marker; $u$ is an $n$-vector of random effects; $\varepsilon$ is an $n$-vector of errors; $\tau^{-1}$ is the variance of the residual errors; $\lambda$ is the ratio between the two variance components; $\mathrm{K}$ is a known $\mathrm{n} \times \mathrm{n}$ relatedness matrix and $I_{n}$ is an $\mathrm{n} \times \mathrm{n}$ identity matrix. $\mathrm{MVN}_{n}$ denotes the n-dimensional multivariate normal distribution. Relatedness matrix $\mathrm{K}$ was calculated as following:

$$
\mathrm{K}=\frac{1}{p} \sum_{i=1}^{p}\left(x_{i}-1_{n} \bar{x}_{i}\right)\left(x_{i}-1_{n} \bar{x}_{i}\right)^{T}
$$

$x_{i}$ as its $i$ th column representing genotypes of $i$ th SNP, $\bar{x}_{i}$ as the sample mean, and $1_{n}$ as a $\mathrm{n} \times 1$ vector of 1 's. GEMMA tests the alternative hypothesis $H_{1}: \beta \neq 0$ against the null hypothesis $H_{0}: \beta=0$ for each SNP. To correct for multiple hypothesis testing, we obtained adjusted $\mathrm{p}$ values by using the Benjamini and Hochberg false discovery rate procedure (Benjamini and Hochberg, 1995), adjusted p-value 0.2 significance level is used. An overview of the test results was shown as a Manhattan plot constructed by the statistical package R. Base pair position of SNP markers were given based on the chicken genome assembly build WASHUC2. Inflation factor was calculated by the $R$ package GenABEL with "median" option (Aulchenko et al., 2007).

\section{Estimating genetic variance}

We estimated the genetic variance of plumage by using GCTA (Yang et al., 2011). After calculating the genetic relationship matrix (GRM) between all pairs of samples using all the autosomal SNPs, we estimated the genetic component, or heritability, for each trait by REML analysis of an Mixed Linear Model $y=X \beta+g_{G}+\varepsilon$, where $y$ is a vector of phenotypes, $\beta$ is a vector of fixed effect such as sex, age with its incidence matrix $\mathrm{X}, \mathrm{g}_{\mathrm{G}}$ is a vector of aggregate $\mathrm{SNP}$ effects as random effect with $\operatorname{Var}\left(\mathrm{g}_{\mathrm{G}}\right)=\mathrm{A}_{\mathrm{G}} \sigma_{\mathrm{G}}^{2}$, and $\mathrm{A}_{\mathrm{G}}$ is the GRM estimated from all autosomal SNPs. We defined heritability or the proportion of variance explained by all autosomal SNPs as $h_{\mathrm{G}}^{2}=\sigma_{\mathrm{G}}^{2} / \sigma_{\mathrm{P}}^{2}$.

\section{RESULTS AND DISCUSSION}

\section{Plumage color of KNC H strain}

Each of the $245 \mathrm{KNC}$ ( $\mathrm{H}$ strain) was investigated individually for plumage coloration (Figure 1). The predominant plumage color of $\mathrm{KNC} \mathrm{H}$ strain chickens was black, but 88 out of 245 had brown feathers in addition to the black. This mixing of brown plumage causes the uniformity of Woorimatdag to decrease. Plumage color was investigated in six body-parts: head, neck, breast, back, wings and tail. One point was given for each body part that showed brown plumage (Table 1). Out of the $207 \mathrm{KNC} \mathrm{H}$ strain hens, 157 hens only had black plumage color, while 41 hens had brown plumage on the neck and 9 hens had brown plumage on both the head and neck. None of the 38 $\mathrm{KNC} \mathrm{H}$ strain roosters were pure black.

Roosters and hens, respectively, have $\mathrm{ZZ}$ and $\mathrm{ZW}$ sex chromosome, which may be the cause of the differential plumage color between sexes. Sex-linked silver locus have been shown to control silver and wild type/gold color and interfere with the coloration of red (Gunnarsson et al., 


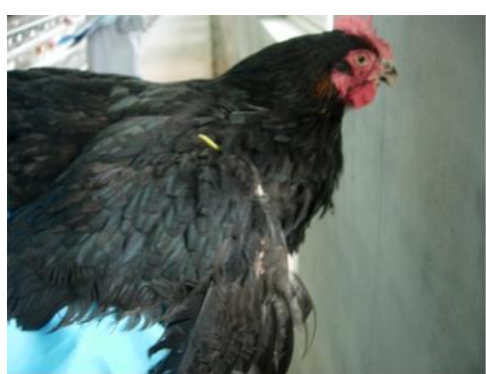

(a)

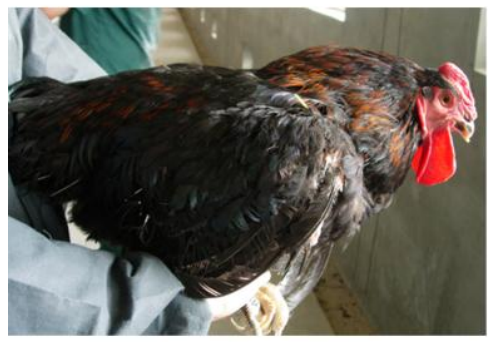

(c)

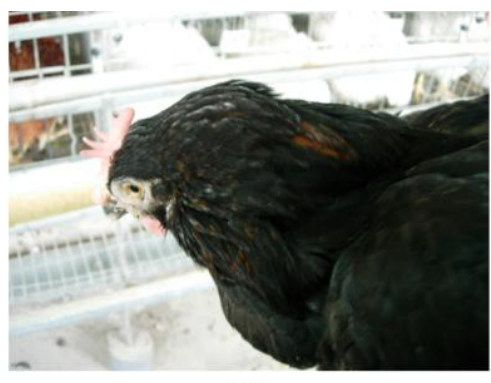

(b)

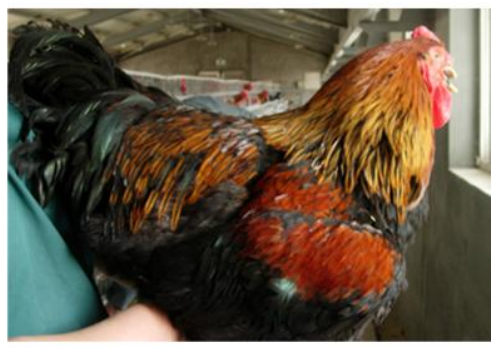

(d)

Figure 1. Example of plumage coloring in chicken. (a) (b) female, (c) (d) male.

2007). This result is estimated to be associated with the difference in the color of the hen and rooster. It is possible that the sex-linked plumage coloration is related to the fact that rooster with colorful plumage has an advantage when it comes to mating success (Brawner III et al., 2000).

\section{The SNPs associated with feather pigmentation}

The genome-wide association study revealed 12 significantly associated SNPs that surpassed the significance level (Figure 2, Table 2). As genomic inflation factor is 0.987 , it can be concluded that the GWAS result is not inflated by considering relatedness using GEMMA (Figure 3). Among the significant SNPs, we identified 4 susceptibility SNPs: rs14339964 (Gga3:36327458, $\mathrm{p}=4.07$ $\left.\times 10^{-9}\right)$, GGaluGA344987 (Gga3:705798, $\left.\mathrm{p}=1.12 \times 10^{-6}\right)$, rs14641648 (Gga8:12987908, $\left.\mathrm{p}=2.06 \times 10^{-6}\right)$, and
GGaluGA193591 (Gga24:5696828, $\left.\mathrm{p}=2.38 \times 10^{-6}\right)$ in the population (Table 2). SNP rs14339964 at Gga3:36327458 is located in an intron region of $A K T 3$ which is known to be regulators of cell signaling in response to insulin and growth factors and involved in a wide variety of biological processes. AKT3 is one of the key genes in the formation of melanoma cells (Tsao et al., 2012). Previous studies reported that through gene-environment interactions pigmentation pathways can contribute to the formation for melanoma and tumours (Gudbjartsson et al., 2008; IbarrolaVillava et al., 2012). Thus, we indirectly infer that AKT3 mutations may be related to plumage pigmentation. Both SNPs, GGaluGA344987 at Gga3:705798 and rs14641648 at Gga8:12987908, are located in an intergenic region around $K R T 7$ and $P A P 2$ which are associated with pigmentation. $P A P 2$ is another name of LPPR5 which has been found to

Table 1. Plumage color pattern of KNC H strain

\begin{tabular}{|c|c|c|c|c|c|c|c|}
\hline \multicolumn{6}{|c|}{ Feather color } & \multirow{2}{*}{ Point } & \multirow{2}{*}{ Number of chickens } \\
\hline Head & Neck & Back & Breast & Wings & Tail & & \\
\hline \multicolumn{8}{|c|}{ 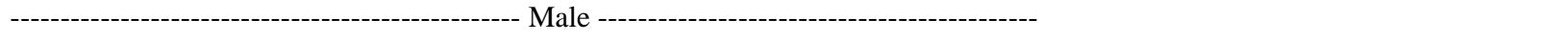 } \\
\hline 0 & 1 & 0 & 0 & 0 & 0 & 1 & 3 \\
\hline 0 & 1 & 1 & 0 & 0 & 0 & 2 & 2 \\
\hline 1 & 1 & 0 & 0 & 1 & 0 & 3 & 9 \\
\hline 1 & 1 & 1 & 0 & 0 & 0 & 3 & 1 \\
\hline 1 & 1 & 1 & 0 & 1 & 0 & 4 & 14 \\
\hline 1 & 1 & 1 & 0 & 1 & 0 & 4 & 4 \\
\hline 1 & 1 & 1 & 1 & 1 & 0 & 5 & 5 \\
\hline & & - & nale - & 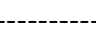 & - & Shank colo & \\
\hline 0 & 0 & 0 & 0 & 0 & 0 & 0 & 157 \\
\hline 0 & 1 & 0 & 0 & 0 & 0 & 0 & 41 \\
\hline 1 & 1 & 0 & 0 & 0 & 0 & 0 & 9 \\
\hline
\end{tabular}

Feather color: $0=$ black, 1 = black+brown. 


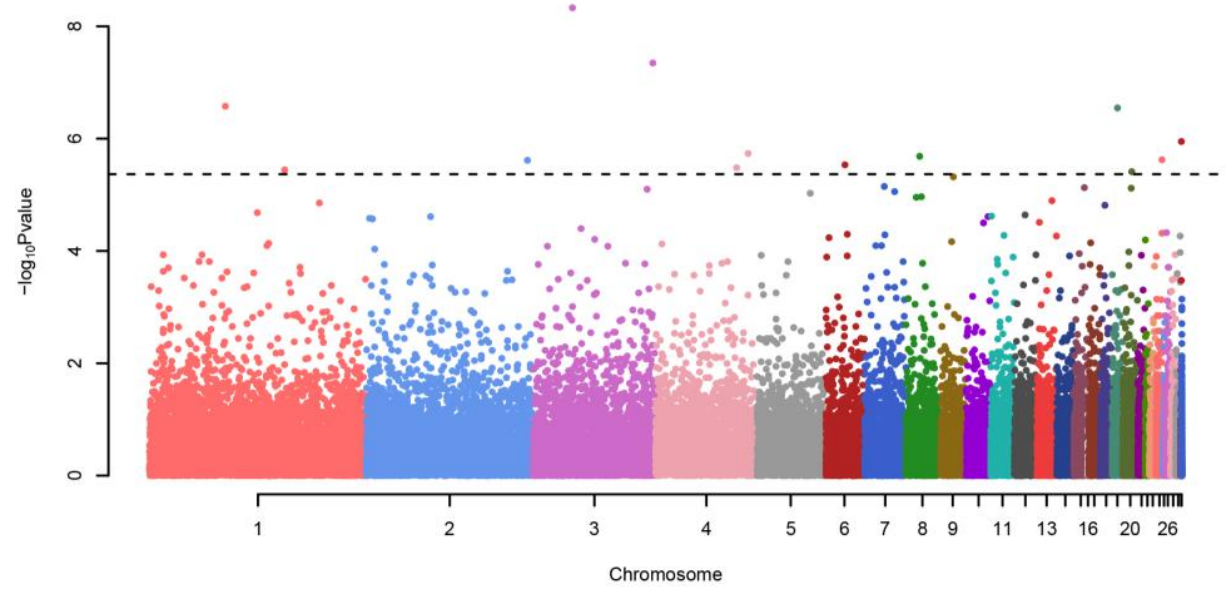

Figure 2. Manhattan plot of GWAS result. GWAS for the integrated phenotypes using Illumina chicken 60K SNP BeadChip of 274 samples. The $\mathrm{x}$-axis of the Manhattan plot shows the genomic position, the y-axis represents the $\log 10$ base transformed p-values, Benjamini and Hochberg false discovery rate procedure (Benjamini and Hochberg, 1995), the dashed line show significance level of adjusted $\mathrm{p}<0.2$.

increase pigmentation (Shan et al., 2009). KRT7 is a member of the keratin gene family and is related with melanocytic tumors (Blum et al., 2010). DDX6 encodes a member of the DEAD box protein family, which has multiple functions including translation suppression and mRNA degradation (Weston and Sommerville, 2006). DDX6 is a previously confirmed gene for vitiligo which is a disease related with pigmentation of skin (Tang et al., 2012). Interestingly, although rs15175679 (Gga20: 8397089, p = $3.91 \times 10^{-6}$ ) is not significant, the variant exits in gga-mir668 which is a region that harbors a small RNA. Previous studies of chicken embryogenesis has shown that this small RNA regulates developmental signaling pathways (Shao et al., 2012). The results of GWAS of head plumage, wing plumage, breast plumage, back plumage, neck plumage and tail plumage traits, separately identified the same SNPs: rs14339964 and rs15616451 (near gene: AKT3, ENSGALG00000020136) as the result of GWAS with the whole body trait. Through the concordant result, we infer that quantitative analysis of whole body plumage is not a simple trait (Table 3).

The feather pigmentation related genes including $M C 1 R$, TYR, PMEL, MLPH, ASIP, SOX10, and SLC34A2 are well known. However, the related loci of these genes were not found in this study. The chicken $60 \mathrm{~K}$ SNP chip does not contain SNPs of the $M C 1 R$ region, and so we could not identify the effects of $M C 1 R$ in this study. The results of this study are nevertheless meaningful in that novel loci affecting pigmentation at genome-wide level were found. Estimated genetic heritability was $18.2 \%$, but estimated

Table 2. Top SNPs associated with plumage coloration

\begin{tabular}{|c|c|c|c|c|c|c|c|c|c|c|c|}
\hline rs & CHR & Position & $\begin{array}{c}\text { Min } \\
/ \mathrm{Maj}^{1}\end{array}$ & Freq & Beta & SE & $\mathrm{p}$ value & Q value* & $\mathrm{g}_{\mathrm{GSNP}} * *$ & Gene & Location \\
\hline rs15304667 & 1 & 70248953 & $\mathrm{G} / \mathrm{A}$ & 0.0623 & 1.221 & 0.230 & $2.66 \mathrm{E}-07$ & 0.014 & 0.143 & STK38L & Intron \\
\hline rs15408789 & 1 & 125252900 & G/A & 0.115 & 0.548 & 0.116 & $3.58 \mathrm{E}-06$ & 0.186 & 0.112 & $A P 1 S 2$ & Intergenic \\
\hline GGaluGA172731 & 2 & 149522175 & G/A & 0.421 & 1.180 & 0.244 & $2.43 \mathrm{E}-06$ & 0.126 & 0.575 & $\begin{array}{l}\text { ENSGALG000 } \\
00018081\end{array}$ & Intergenic \\
\hline rs14339964 & 3 & 36327458 & $\mathrm{~A} / \mathrm{C}$ & 0.210 & 1.186 & 0.194 & $4.70 \mathrm{E}-09$ & 0.000 & 0.394 & AKT3 & Intron \\
\hline GGaluGA239670 & 3 & 110847381 & $\mathrm{G} / \mathrm{A}$ & 0.206 & 1.366 & 0.241 & $4.50 \mathrm{E}-08$ & 0.002 & 0.447 & $T F A P 2 B$ & Intergenic \\
\hline rs 15616451 & 4 & 75015502 & $\mathrm{~A} / \mathrm{G}$ & 0.053 & 0.597 & 0.125 & $3.30 \mathrm{E}-06$ & 0.171 & 0.060 & $\begin{array}{l}\text { ENSGALGOOO } \\
00020136\end{array}$ & Intergenic \\
\hline rs 16445392 & 4 & 85858579 & $\mathrm{~A} / \mathrm{C}$ & 0.025 & 0.908 & 0.186 & $1.85 \mathrm{E}-06$ & 0.096 & 0.044 & $M X D 4$ & Intron \\
\hline rs 15790835 & 6 & 19031740 & $\mathrm{~A} / \mathrm{C}$ & 0.132 & 1.087 & 0.227 & $2.89 \mathrm{E}-06$ & 0.150 & 0.249 & $\begin{array}{l}\text { ENSGALG000 } \\
00005969\end{array}$ & Intergenic \\
\hline rs 14641648 & 8 & 12987908 & $\mathrm{~A} / \mathrm{G}$ & 0.115 & 1.165 & 0.239 & $2.06 \mathrm{E}-06$ & 0.107 & 0.237 & $P A P 2$ & Intron \\
\hline rs 15047928 & 19 & 5092926 & $\mathrm{~A} / \mathrm{G}$ & 0.329 & 1.325 & 0.251 & $2.87 \mathrm{E}-07$ & 0.015 & 0.585 & FAM211A & Intron \\
\hline GGaluGA193591 & 24 & 5696828 & $\mathrm{G} / \mathrm{A}$ & 0.121 & 1.162 & 0.240 & $2.38 \mathrm{E}-06$ & 0.123 & 0.247 & DDX6 & Intron \\
\hline GGaluGA344987 & $\begin{array}{c}\text { E22C19 } \\
\text { W28 }\end{array}$ & 705798 & $\mathrm{G} / \mathrm{A}$ & 0.287 & 1.110 & 0.222 & $1.12 \mathrm{E}-06$ & 0.058 & 0.454 & KRT7 & Intergenic \\
\hline
\end{tabular}




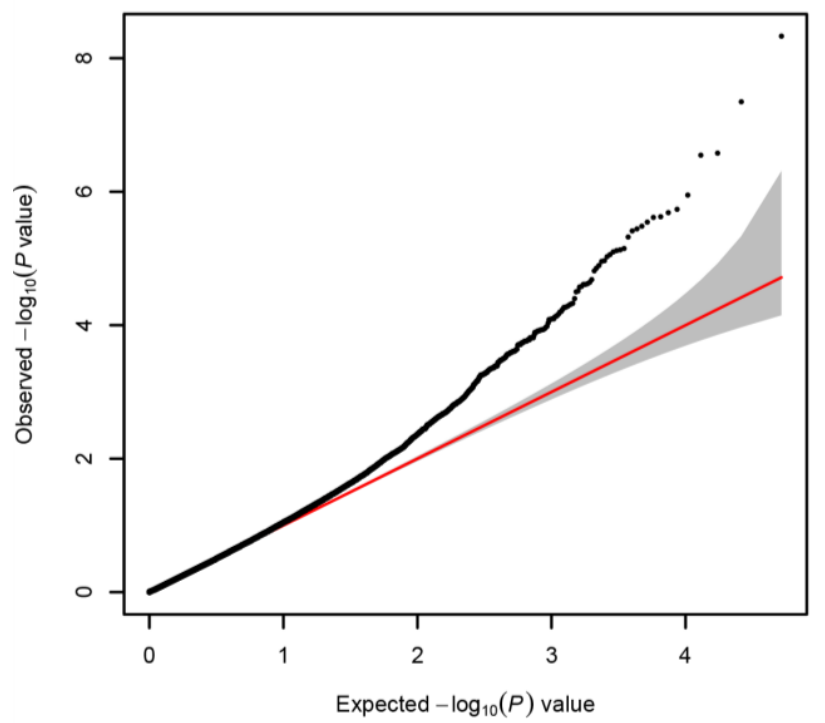

Figure 3. Quantile-Quantile plot of GWAS result Inflation factor (lambda) $=0.9877269$.

Table 3. Top SNPs associated with plumage coloration by each part

\begin{tabular}{|c|c|c|c|c|c|c|c|c|c|c|c|}
\hline $\begin{array}{l}\text { Plumage } \\
\text { part }\end{array}$ & rs ID & CHR & Position & $\begin{array}{l}\text { Min } \\
/ \mathrm{Maj}^{1}\end{array}$ & Freq & Beta & SE & $\mathrm{p}$ value & Q value* & Gene & Location \\
\hline \multirow{5}{*}{ Head } & rs14398623 & 3 & 97933258 & $\mathrm{~A} / \mathrm{G}$ & 0.115 & -0.149 & 0.030 & $1.56 \mathrm{E}-06$ & 0.081 & RNF144A & Intron \\
\hline & rs318020030 & 7 & 19055437 & $\mathrm{~A} / \mathrm{G}$ & 0.350 & 0.220 & 0.045 & $1.79 \mathrm{E}-06$ & 0.093 & $P P P 1 R 9 B$ & Intron \\
\hline & rs16669242 & 9 & 14516013 & $\mathrm{~A} / \mathrm{C}$ & 0.296 & 0.235 & 0.041 & $2.74 \mathrm{E}-08$ & 0.001 & $F G F 12$ & Intergenic \\
\hline & GGaluGA105119 & 14 & 14228307 & $\mathrm{G} / \mathrm{A}$ & 0.321 & 0.154 & 0.032 & $2.76 \mathrm{E}-06$ & 0.144 & $\begin{array}{l}\text { ENSGALG000 } \\
00023628\end{array}$ & Intergenic \\
\hline & rs14112979 & 18 & 7210201 & $\mathrm{G} / \mathrm{A}$ & 0.341 & 0.219 & 0.042 & $3.26 \mathrm{E}-07$ & 0.017 & $H E L Z$ & Intron \\
\hline \multirow[t]{7}{*}{ Wing } & rs13982792 & 1 & $1.83 \mathrm{E}+08$ & $\mathrm{~A} / \mathrm{G}$ & 0.463 & 0.153 & 0.033 & $3.48 \mathrm{E}-06$ & 0.181 & XPO4 & Intron \\
\hline & rs14131527 & 2 & 4895894 & $\mathrm{~A} / \mathrm{G}$ & 0.346 & 0.114 & 0.022 & 4.14E-07 & 0.022 & XIRP1 & Intron \\
\hline & rs14188826 & 2 & 59639362 & $\mathrm{~A} / \mathrm{G}$ & 0.058 & 0.163 & 0.034 & $2.70 \mathrm{E}-06$ & 0.140 & $P R L$ & Intergenic \\
\hline & rs14339964 & 3 & 36327458 & $\mathrm{~A} / \mathrm{C}$ & 0.210 & 0.146 & 0.029 & $1.19 \mathrm{E}-06$ & 0.062 & AKT3 & Intron \\
\hline & rs14404313 & 3 & 103537929 & $\mathrm{C} / \mathrm{A}$ & 0.146 & 0.203 & 0.036 & $3.75 \mathrm{E}-08$ & 0.002 & $N T 5 C 1 B$ & Intergenic \\
\hline & GGaluGA110134 & 15 & 9605683 & $\mathrm{G} / \mathrm{A}$ & 0.333 & 0.175 & 0.037 & $3.52 \mathrm{E}-06$ & 0.184 & MSII & Intron \\
\hline & rs15027075 & 17 & 10503821 & $\mathrm{~A} / \mathrm{G}$ & 0.357 & 0.111 & 0.023 & $2.70 \mathrm{E}-06$ & 0.141 & $P B X 3$ & Intron \\
\hline Breast & rs 14316836 & 3 & 7925459 & $\mathrm{G} / \mathrm{A}$ & 0.293 & 0.062 & 0.013 & $2.49 \mathrm{E}-06$ & 0.129 & LCLATI & Intron \\
\hline \multirow[t]{5}{*}{ Back } & rs 14401050 & 3 & 100155987 & $\mathrm{~A} / \mathrm{G}$ & 0.204 & 0.174 & 0.036 & $2.23 \mathrm{E}-06$ & 0.116 & E2F6 & Intergenic \\
\hline & rs15616451 & 4 & 75015502 & $\mathrm{~A} / \mathrm{G}$ & 0.053 & 0.118 & 0.024 & $1.71 \mathrm{E}-06$ & 0.089 & $\begin{array}{l}\text { ENSGALG000 } \\
00020136\end{array}$ & Intergenic \\
\hline & GGaluGA287070 & 5 & 49185847 & G/A & 0.393 & 0.198 & 0.038 & 4.53E-07 & 0.024 & VRK1 & Intergenic \\
\hline & GGaluGA095084 & 13 & 11601056 & $\mathrm{G} / \mathrm{A}$ & 0.082 & 0.175 & 0.033 & $1.81 \mathrm{E}-07$ & 0.009 & $S G C D$ & Intron \\
\hline & rs15022353 & 15 & 7826821 & $\mathrm{~A} / \mathrm{G}$ & 0.216 & 0.178 & 0.029 & $1.84 \mathrm{E}-09$ & $9.56 \mathrm{E}-05$ & TTC28 & Intron \\
\hline
\end{tabular}

${ }^{1}$ Minor allele/Major allele. * Adjusted $\mathrm{p}$ value.

genetic heritability of significant SNPs was $3.1 \%$. The results support a polygenic effect in feather pigmentation. This means previously reported genes MC1R, TYR, PMEL, $M L P H, A S I P, S O X 10$, and SLC34A2 as well as the reported loci in this study are important in plumage coloration. The results may contribute to selecting and breeding of $\mathrm{KNC} \mathrm{H}$ for plumage color uniformity.

\section{ACKNOWLEDGEMENTS}

The work was supported by a grant from the AGENDA project (No. PJ907057) in the National Institute of Animal Science, Rural Development Administration (RDA), Republic of Korea.

\section{REFERENCES}

Aulchenko, Y. S., S. Ripke, A. Isaacs, and C. M. van Duijn. 2007. GenABEL: an R library for genome-wide association analysis. Bioinformatics 23:1294-1296.

Benjamini, Y. and Y. Hochberg. 1995. Controlling the false discovery rate: a practical and powerful approach to multiple 
testing. J. Roy. Stat. Soc. 57:289-300.

Blum, A., K. Hartmann and A. Rütten. 2010. Bräunliche Verfärbung der linken Brustwarze bei einer 60-jährigen Patientin. Der Hautarzt 61:64-68.

Brawner III, W. R., G. E. Hill, and C. A. Sundermann. 2000. Effects of coccidial and mycoplasmal infections on carotenoidbased plumage pigmentation in male house finches. The Auk 117:952-963.

Gudbjartsson, D. F., P. Sulem, S. N. Stacey, A. M. Goldstein, T. Rafnar, B. Sigurgeirsson, K. R. Benediktsdottir, K. Thorisdottir, R. Ragnarsson, and S. G. Sveinsdottir. 2008. ASIP and TYR pigmentation variants associate with cutaneous melanoma and basal cell carcinoma. Nat. Genet. 40:886-891.

Gunnarsson, U., A. R. Hellström, M. Tixier-Boichard, F. Minvielle, B. Bed'Hom, S. I. Ito, P. Jensen, A. Rattink, A. Vereijken, and L. Andersson. 2007. Mutations in SLC45A2 cause plumage color variation in chicken and Japanese quail. Genetics 175:867-877.

Heo, K.-N., H.-J. Choo, B.- Y. Seo, M.-N. Park, K.-C. Jung, B.-J. Hwang, H.-K. Kim, E.-C. Hong, O.-S. Seo, and B.-S. Kang. 2011. Investigation of $T Y R$ and $M C 1 R$ polymorphism in Korean native chickens and the commercial chickens. CNU J. Agr. Sci. 38:465-471.

Ibarrola-Villava, M., H.-H. Hu, M. Guedj, L. P. Fernandez, V. Descamps, N. Basset-Seguin, M. Bagot, A. Benssussan, P. Saiag, and M. C. Fargnoli. 2012. MC1R, SLC45A2 and TYR genetic variants involved in melanoma susceptibility in Southern European populations: Results from a Meta-analysis. Eur. J. Cancer 48:2183-2191.

Kerje, S., J. Lind, K. Schütz, P. Jensen, and L. Andersson. 2003. Melanocortin 1-receptor (MC1R) mutations are associated with plumage colour in chicken. Anim. Genet. 34:241-248.

Klungland, H. and D. Vage. 2000. Molecular genetics of pigmentation in domestic animals. Curr. Genomics 1:223-242.

Liu, W., S. Chen, J. Zheng, L. Qu, G. Xu, and N. Yang. 2010. Developmental phenotypic-genotypic associations of tyrosinase and melanocortin 1 receptor genes with changing profiles in chicken plumage pigmentation. Poult. Sci. 89:11101114.
Park, M.-N., E.-C. Hong, B.-S. Kang, H.-K. Kim, J.-H. Kim, S.-H. Na, H.-S. Chae, O.-S. Seo, J.-Y. Han, J.-H. Jeong, and B.-J. Hwang. 2010. Chemical composition and meat quality of crossbred Korean native chickens (KNC). Korean J. Poult. Sci. 37:415-421.

Purcell, S., B. Neale, K. Todd-Brown, L. Thomas, M. Ferreira, A. D. Bender, J. Maller, P. Sklar, P. I. De Bakker, and M. J. Daly. 2007. PLINK: a tool set for whole-genome association and population-based linkage analyses. Am. J. Hum. Genet. 81:559-575.

Shan, X., Y. Zhang, W. Peng, Z. Wang, and D. Xie. 2009. Molecular mechanism for jasmonate-induction of anthocyanin accumulation in Arabidopsis. J. Exp. Bot. 60:3849-3860.

Shao, P., J.-Y. Liao, D.-G. Guan, J.-H. Yang, L.-L. Zheng, Q. Jing, H. Zhou, and L.-H. Qu. 2012. Drastic expression change of transposon-derived piRNA-like RNAs and microRNAs in early stages of chicken embryos implies a role in gastrulation. RNA Biol. 9:212-227.

Tadano, R., M. Sekino, M. Nishibori, and M. Tsudzuki. 2007. Microsatellite marker analysis for the genetic relationships among Japanese long-tailed chicken breeds. Poult. Sci. 86:460469.

Tang, X.-F., Z. Zhang, D.-Y. Hu, A.-E. Xu, H.-S. Zhou, L.-D. Sun, M. Gao, T.-W. Gao, X.-H. Gao, and H.-D. Chen. 2012. Association analyses identify three susceptibility loci for vitiligo in the Chinese Han population. J. Invest. Dermatol. 133:403-410

Tsao, H., L. Chin, L. A. Garraway, and D. E. Fisher. 2012. Melanoma: from mutations to medicine. Genes Dev. 26:11311155.

Weston, A. and J. Sommerville. 2006. Xp54 and related (DDX6like) RNA helicases: roles in messenger RNP assembly, translation regulation and RNA degradation. Nucleic Acids Res. 34:3082-3094.

Yang, J., S. H. Lee, M. E. Goddard, and P. M. Visscher. 2011. GCTA: a tool for genome-wide complex trait analysis. Am. J. Hum. Genet. 88:76-82.

Zhou, X. and M. Stephens. 2012. Genome-wide efficient mixedmodel analysis for association studies. Nat. Genet. 44:821-824. 